\title{
Decisions With Patients and Families Regarding Aducanumab in Alzheimer Disease, With Recommendations for Consent
}

\author{
AAN Position Statement
}

Winston Chiong, MD, PhD, Benjamin David Tolchin, MD, MS, Richard J. Bonnie, LLB, Katharina M. Busl, MD, MS, Salvador Cruz-Flores, MD, Leon G. Epstein, MD, Ericka P. Greene, MD, Judy Illes, CM, PhD,

Matthew Kirschen, MD, PhD, Daniel G. Larriviere, MD, JD, Sneha Mantri, MD, Michael A. Rubin, MD,

Barney J. Stern, MD, and Lynne P. Taylor, MD, on behalf of the Ethics, Law, and Humanities Committee (a joint committee of the AAN, ANA, and CNS)

Neurology ${ }^{\circledR}$ 2022;98:154-159. doi:10.1212/WNL.0000000000013053

Alzheimer disease $(\mathrm{AD})$ is a feared and stigmatized condition, with relentlessly progressive impact not only on the independence and health of people with dementia, but also on the health and financial well-being of their families, and the overall health care system and society. Further research towards effective treatment for $\mathrm{AD}$ is urgently needed, and patients with $\mathrm{AD}$ deserve more support from clinicians and from their communities. One essential condition of this support is trust. Whereas it is important to offer hope to patients and families, these efforts will ring hollow if trust is lost. Neurologists and others who serve patients and the broader public health must continually ask: Are the statements and actions of our profession worthy of the trust placed in us by patients and the public?

Neurologists have often depended upon US Food and Drug Administration (FDA) approval as a sign of a medication's safety and effectiveness, but recent decisions indicate a lowering of the standards of scientific evidence used for drug approvals, ${ }^{1-3}$ which will require clinicians to scrutinize approved medications more carefully. One recent example is the approval of aducanumab, a monoclonal antibody directed at $\beta$-amyloid aggregates implicated in the pathogenesis of $\mathrm{AD}$. Although drug approval has traditionally depended on support from 2 well-conducted clinical trials, aducanumab was approved based upon 2 studies that were both stopped prematurely for futility. In later post hoc analyses of the available data, 1 trial indicated a statistically significant but small benefit with high-dose aducanumab, while the other study continued to indicate no benefit. The clinical importance of the small statistical benefit in 1 trial for daily function is unclear, and aducanumab was also associated with brain swelling and hemorrhage in more than one-third of patients who received the dose approved by the FDA. An advisory committee of outside experts convened by the FDA reviewed the available evidence and decisively concluded ( 10 votes no, 1 uncertain) that these data did not support a conclusion that aducanumab slows cognitive decline.

The FDA approved aducanumab by invoking the accelerated approval pathway rather than the traditional approval process. This contradicted prior assurances by the agency that the determination would depend on clinical endpoints. ${ }^{4}$ Instead, as an accelerated approval, the FDA based its decision on the effects of aducanumab on brain $\beta$-amyloid levels as a surrogate marker

MORE ONLINE

(ค) Podcast

NPub.org/Podcast9804

From the Department of Neurology (W.C.), University of California San Francisco; Department of Neurology (B.D.T.), Yale School of Medicine, New Haven, CT; School of Law (R.J.B.) University of Virginia, Charlottesville; Departments of Neurology and Neurosurgery (K.M.B.), University of Florida, Gainesville; Department of Neurology (S.C.-F.), Paul L. Foster School of Medicine, Texas Tech University Health Sciences Center, El Paso; Departments of Neurology and Pediatrics (L.G.E.), Northwestern University Feinberg School of Medicine, Chicago, IL; Department of Neurology (E.P.G.), Houston Methodist Hospital, TX; Neuroethics Canada and Division of Neurology (.I.), University of British Columbia, Vancouver, Canada; Departments of Anesthesia \& Critical Care, Pediatrics, and Neurology (M.K.), Children's Hospital of Philadelphia, Pennsylvania; Neuroscience Service Line, Inova Health System (D.G.L.), Falls Church, VA; Department of Neurology (S.M.), Duke University, Durham, NC; Departments of Neurology and Neurological Surgery (M.A.R.), University of Texas Southwestern Medical Center, Dallas; Department of Neurology (B.J.S.), Johns Hopkins University, Baltimore, MD; and Departments of Neurology and Neurosurgery (L.P.T.), University of Washington, Seattle.

Go to Neurology.org/N for full disclosures. Funding information and disclosures deemed relevant by the authors, if any, are provided at the end of the article.

Approved by the Ethics, Law, and Humanities Committee, a joint committee of the American Academy of Neurology (AAN), American Neurological Association (ANA), and Child Neurology Society (CNS), on July 23, 2021. Approved by the AAN on August 19, 2021; the ANA on September 22, 2021; and the CNS on November 1, 2021. 


\section{Glossary}

AD = Alzheimer disease; ARIA = amyloid-related imaging abnormalities; FDA = Food and Drug Administration; $\mathbf{M C I}=$ mild cognitive impairment.

of reasonably likely clinical benefit. Whereas surrogate markers may be useful when circumstances preclude measurement of clinical outcomes, insufficient reason was given by the agency for appealing to a surrogate marker for a case in which clinical outcomes were measured but insufficient for approval. Such additional explanation is crucial because the link between brain $\beta$-amyloid reduction and clinically meaningful outcomes in patients with symptomatic $\mathrm{AD}$ remains unclear. ${ }^{5}$ Three members of the advisory committee have since resigned to protest the FDA's decision. ${ }^{6}$

A second source of broad ethical concern is the announcement by Biogen, the developer of aducanumab, of the $\$ 56,000$ USD yearly cost of the drug. This price does not include costs related to infusion services, increased physician follow-up, or the additional studies required to monitor for risks associated with use of the drug (detailed below). Medicare Part B in the United States pays only $80 \%$ of the cost of most covered drugs and services. If this general approach is applied by Medicare to aducanumab, many beneficiaries would pay thousands of dollars of out-of-pocket costs for a drug with substantial risks and without proven clinical benefit. ${ }^{7}$ This is a substantial burden for patients and families as the median annual income of Medicare beneficiaries is $\$ 29,650$ and many are on fixed incomes. Medicare spending has been projected to increase by billions of dollars as a result of aducanumab's approval, threatening the financial viability of the program and increasing Part B premiums for all enrollees. Such burdens are likely to have their own negative effects on public health. The very high price of aducanumab also creates misaligned incentives for clinics, which are reimbursed according to a percentage of the cost of infusion drugs. ${ }^{8}$

The unusual approval process increases the decisional burden on clinicians, patients, and families, who must now deliberate about how to manage treatment of a dreaded illness with a novel intervention that imposes significant costs and harms without clear evidence of benefit. This environment, combined with the potential for worrisome financial conflicts of interest, could place strains on the patient-physician relationship and on fundamental ethical principles that govern the practice of neurology.

The American Academy of Neurology aims to support clinicians, patients, and families in navigating these challenging decisions. In this position statement, we examine specific ethical considerations bearing on use of aducanumab based on a widely accepted framework of principles in biomedical ethics ${ }^{9}$ and offer recommendations for informed consent.

\section{Beneficence}

The ethical principle of beneficence requires physicians to provide care in the best medical interests of patients based upon scientific evidence. Aducanumab was approved without convincing evidence of clinical benefit, and with known harms (discussed below under nonmaleficence). Neurologists should be aware that clinical trials were conducted in a narrowly selected population of patients with mild cognitive impairment (MCI) or very early dementia due to $\mathrm{AD}$ (MiniMental State Examination score $\geq 24$, Clinical Dementia Rating 0.5 ), and with biomarker evidence of brain $\beta$-amyloid deposition. Outside these inclusion criteria, safety and efficacy data are lacking, and there is no physiologic rationale for the use of this medication in patients without brain $\beta$-amyloid deposition. Under the principle of beneficence, therefore, there are insufficient grounds to warrant offering aducanumab to patients with moderate or advanced dementia due to $\mathrm{AD}$, or to patients without biomarker evidence of brain $\beta$-amyloid.

Patients within the original trial inclusion criteria should be made aware that aducanumab has not been demonstrated to improve clinical outcomes and that possible clinical benefits are modest. There is no prospect of curing $\mathrm{AD}$ or restoring cognitive function with aducanumab. The 2 pivotal clinical trials of aducanumab collectively enrolled 3,290 patient participants in a narrowly selected population and so were initially powered to detect small clinical differences. In 1 trial, aducanumab was associated with slowed progression equivalent to a difference of 4 months out of 18 , and in the other trial with a difference of 0 months. Also, as the intended benefit would be a partial slowing rather than cessation of cognitive decline, whether treatment is achieving a clinical effect for any individual patient may be unclear.

Another major threat to the principle of beneficence is the potential for financial conflicts of interest that compromise the obligation of neurologists to direct care towards the medical benefit of patients and not to their own personal benefit. The risk of misaligned interests is particularly grave for a medication without established clinical benefit, with substantial risks, and with large financial incentives. Clinics will initially be reimbursed at $103 \%$ of aducanumab's wholesale acquisition cost of $\$ 56,000$ for a patient of average weight, and later will be reimbursed at $104.3 \%$ of the average sale price. ${ }^{10}$ Particularly for those able to negotiate a lower sale price, clinics will realize thousands of dollars in profit per patient for the drug alone, even prior to professional fees and services such as infusion and imaging. Misaligned incentives can have a corrupting effect on practice, particularly when 
undisclosed. Markups of thousands of dollars per patient, as a source of revenue entirely dependent on a decision to administer an intervention without proven benefit to patients, are sufficiently large to require disclosure of these interests when neurologists offer recommendations about treatment.

\section{Key Points}

- There are insufficient grounds to warrant offering aducanumab to patients with moderate or advanced dementia due to $\mathrm{AD}$ or patients without biomarker evidence of brain $\beta$-amyloid.

- Aducanumab will not cure $\mathrm{AD}$ or restore cognitive function.

- Potential financial conflicts of interest compromise the duty of beneficence in patient care.

\section{Nonmaleficence}

The principal medical risk of treatment with aducanumab is brain inflammation, referred to as amyloid-related imaging abnormalities (ARIA), which involves brain edema, brain hemorrhage, or a combination of the two. These abnormalities occur in more than one-third of patients receiving the approved dose of aducanumab, with increased risk among carriers of the ApoE4 allele. In clinical trials, ARIA was usually detected incidentally on screening MRIs, but 1 in 10 patients receiving full-dose aducanumab had symptoms and signs such as headache, confusion, dizziness, vision changes, nausea, and vomiting. In rare cases, severe symptoms may include seizure, focal neurologic deficits referable to affected brain regions, and malignant hypertension requiring measures such as hospitalization and intensive care. In most cases, symptoms or imaging findings resolved or stabilized with temporary cessation of aducanumab, but 1 in 14 patients randomized to full-dose treatment were permanently removed from clinical trials due to persistent ARIA. The FDA label calls for less frequent monitoring than was performed in clinical trials, with screening MRIs performed prior to the 7 th and 12th dose; additional MRIs will often be needed in response to changes in patients' clinical condition. This includes symptoms such as confusion that are nonspecific and common in patients with MCI and mild dementia due to AD. Neurologists must communicate information about potential adverse effects and the burdens of monitoring and should assist patients and families in quantifying complex information in familiar terms.

In addition to medical harms, the pricing and coverage of aducanumab may cause financial harm to patients and families, depending on how Medicare addresses the individual patient and system costs of this highly expensive medication. Considering charges for infusion services, repeated imaging, and medical management (in rare cases including hospitalization for severe symptoms), treatment costs may exceed $\$ 100,000$ per patient per year, of which Medicare generally covers $80 \%$. Ten percent of Medicare beneficiaries are in traditional Medicare with no supplemental coverage, and they could be fully exposed to cost-sharing requirements for the remaining 20\% of expenses. Beneficiaries enrolled in Medicare Advantage plans would be responsible for their share of costs until they reach the annual out-of-pocket maximum ( $\$ 7,550$ for in-network and $\$ 11,300$ for out-of-network care). Beneficiaries with Medigap, retiree benefits, or who are dually eligible for Medicaid would have some coinsurance costs covered, though those with Medigap or retiree benefits are likely to pay increasing premiums given increases in plan liability for aducanumab coverage. Some patients and families will be unaware of the specifics of their coinsurance coverage, especially for clinician-administered Part B medications as opposed to outpatient Part D prescriptions, and could be exposed to substantial unexpected financial costs. Neurologists should inform patients and families that the full costs of treatment may not be covered by Medicare or their insurance, and should emphasize the importance of understanding their coinsurance obligations and the financial ramifications of decisions to pursue treatment. At a policy level, stakeholders are being convened to propose measures to mitigate these burdens, although it is unclear whether these efforts will be successful or what unintended consequences any proposed remedies may have.

\section{Key Points}

- Neurologists must communicate potential adverse effects and the burdens of monitoring. Given the complexities of the data and the unfamiliarity of some of the medical risks, many patients and families will require extended discussions using accessible language to assist them in weighing these burdens.

- Neurologists have a responsibility to inform patients and families that the full costs of treatment may not be covered and about the financial ramifications of decisions to pursue treatment.

\section{Justice}

Although neurologists do not make resource allocation decisions at the bedside, neurologists should be guided in clinical interactions and in their broader public advocacy by the ethical principle of justice. This principle calls on neurologists to consider whether the benefits, risks, and burdens of interventions are fairly distributed, and demands particular attention given growing awareness of historic inequities in medical care. Given its price and the high prevalence of $\mathrm{AD}$, even conservative estimates of aducanumab utilization have staggering implications for health system costs. There are 6.2 million Americans with $\mathrm{AD}$ who are age 65 years or older and roughly 5 million older Americans with $\mathrm{MCI}$ due to $\mathrm{AD} .{ }^{10}$ If only 1 in $20^{11}$ of these potential patients is prescribed aducanumab, which is below the developer's projections, ${ }^{12}$ total annual spending for this drug by Medicare would exceed \$25 billion. This is more than 3 times as much as Medicare spent 
to cover any other part B or part D drug in $2019 .{ }^{13}$ Including out-of-pocket costs paid by beneficiaries and other clinical services, treating this small fraction of potential patients would increase total US health expenditures by $1.5 \%{ }^{14}$ This will increase burdens on taxpayers and increase premiums for Medicare beneficiaries, for a medication without established clinical benefit, when many pressing care needs for people with $\mathrm{AD}$ and their families, such as home health aides, wage supports for caregivers, legal aid, and long-term care, remain chronically underfunded.

Enrollment in clinical trials for aducanumab reflected historic patterns of exclusion that are all too familiar in health care. Fewer than $3 \%$ of participants enrolled were Hispanic and fewer than $1 \%$ were Black or Indigenous. This not only deprives potential patients from underserved groups of relevant information about the benefits and harms of a proposed treatment, ${ }^{15}$ but also imposes unjust burdens on taxpayers of these backgrounds, who share in the substantial societal costs of paying for an intervention for which no conclusions can be drawn about its relative safety or efficacy in their case.

According to the reasonable patient standard of informed consent-a legal requirement in about half of US states and an ethical standard for informed consent more broadlyclinicians are obligated to disclose information that a reasonable patient would consider material to a treatment decision. Many Hispanic, Black, and Indigenous patients would consider materially relevant that all available safety data regarding aducanumab effectively exclude people of their backgrounds. Given the magnitude of potential harms and uncertain benefits of aducanumab, informed consent conversations with patients of populations underrepresented in clinical trials should include disclosure about the absence of safety and efficacy data in these groups.

\section{Key Points}

- The absence of racial and ethnic diversity in the clinical trials of aducanumab is a significant concern for justice.

- Informed consent conversations with patients of populations underrepresented in clinical trials should include disclosure about the absence of safety and efficacy data in these groups.

\section{Autonomy}

News and media coverage of a new treatment for $\mathrm{AD}$ will necessitate detailed conversations among neurologists, patients, and families about an intervention (1) that should not be offered to patients with moderate or advanced dementia, or who have other contraindications, and (2) for which clinical benefits for any patient have not been convincingly demonstrated. One danger is that this will draw time and attention away from patient and family counseling about matters, especially in early stages of disease, that will often be more consequential for the care of patients. Such topics include advance medical and financial planning, driving, accommodations to maintain functional independence, home safety, and caregiver support. Clinicians and patients may often feel desperation to do anything that might help in efforts to stop a feared illness, yet while neurologists are medical professionals, they should remember that the most important interventions for many patients and families are nonmedical. ${ }^{16}$

Respect for patient autonomy in complex medical decisions is best demonstrated through the process of shared decisionmaking. In this model, patients are experts about their values, and thus about what is of greatest importance when tradeoffs must be made. Meanwhile, physicians offer expertise about evidence and physiology, and as such should seek to interpret patients' values and offer guidance about the medical course of action that best serves those values. Thus, respect for autonomy is not simply a matter of acceding to initial requests for treatment, but instead calls for a shared process of understanding and interpreting the values that motivate patients' wishes. This process can then inform recommendations about the medical course of action that promotes those values.

Medical decision-making about aducanumab, therefore, should include discussion of patients' and families' expectations regarding the likelihood and magnitude of benefit, how they weigh potential benefits against medical risks, and about patients' values more generally. Given the absence of convincing scientific evidence of benefit, known potential harms, burdensome monitoring, and financial costs of aducanumab, neurologists should carefully consider whether aducanumab can be recommended to individual patients as the medical course of action that best serves their values. Several major health systems and insurers have elected not to offer aducanumab to any patients given such concerns. ${ }^{17}$ Neurologists should also continue to consider enrolling patients in clinical trials, which also involve interventions of unproven efficacy and potential harms of similar magnitude, but are of social benefit and do not present similar risks of financial harm to patients and their families.

Because aducanumab should be considered only in MCI or very early dementia due to $\mathrm{AD}$, shared decision-making should generally include patients with capacity rather than rely solely on a surrogate decision-maker, although supportive family involvement will also often be beneficial. If after such a discussion a patient believes that aducanumab is the best course of treatment, and if the patient meets appropriate eligibility criteria, a neurologist who judges that treatment is reasonable for an individual patient may prescribe aducanumab based on this process of shared decisionmaking and a documented informed consent conversation that includes the recommended elements listed (sidebar). However, if in a neurologist's professional judgment the potential harms of treatment with aducanumab for an individual patient outweigh the anticipated benefits, the neurologist is ethically obligated to decline to offer such a treatment. 


\section{Key Points}

- Respect for patient autonomy in complex medical decisions is best demonstrated through the process of shared decisionmaking, in which clinicians play an active role in interpreting patients' values and recommending care that promotes those values.

- Respect for patient autonomy does not require clinicians to offer treatments for which the potential harms, in their judgment, outweigh the anticipated benefits.

\section{Discussion}

Effective treatments for $\mathrm{AD}$ are urgently needed given the tremendous burdens of this disease on both a personal and societal level. Aducanumab is very far from a cure for $\mathrm{AD}$. Whereas many hope that its approval will lead to better treatments in the future, there are also grounds to worry that its availability will hinder enrollment in clinical trials of more effective interventions. In the interim, neurologists, patients, and families will face ethical challenges given the incomplete data available to guide aducanumab prescribing, the prospect of worrisome financial conflicts of interest, and the costs and practical burdens that using aducanumab will impose on patients and families. Neurologists facing these challenges will be guided best by established ethical principles that they can apply, in turn, to transparently counsel patients and their families. Future research and public advocacy must strive towards effective treatments that are supported by rigorous scientific evidence, that address the needs of all patients including those who are underserved, and that make it easier rather than harder for society to address the full range of care needs of people with $\mathrm{AD}$ and other dementias.

\section{Recommended Discussion Elements for Informed Consent}

Discussion regarding potential benefits:

- Absence of convincing scientific evidence of efficacy

- Potential benefits are modest with no prospect of cure or restoring cognition even if clinical trial data are interpreted optimistically

Discussion regarding risks/burdens:

- Risks of cerebral edema, hemorrhage, and hospitalization; this includes efforts to quantify the risk of cerebral edema and hemorrhage (e.g., >1/3) and the risk of symptomatic ARIA (e.g., 1 in 10)

- Burdens of administration and monitoring, including infusion frequency and MRI

- Financial costs to the patient and family, including Medicare copayments; it is important to emphasize coinsurance obligations and the financial ramifications of pursuing treatment
Broader considerations:

- Financial interests of the physician, practice group, or institution in aducanumab may create a conflict of interest regarding recommendations of its use

- Clinical trials of aducanumab were conducted in cohorts from which patients of Black, Indigenous, or Hispanic backgrounds were generally not included; the relative efficacy and safety of this medication in excluded groups have not been adequately addressed

\section{Study Funding}

No targeted funding reported.

\section{Disclosure}

Go to Neurology.org/N for full disclosures.

\section{Publication History}

Received by Neurology August 20, 2021. Accepted in final form November 2, 2021.

Appendix Authors

\begin{tabular}{|c|c|c|}
\hline Name & Location & Contribution \\
\hline $\begin{array}{l}\text { Winston Chiong, } \\
\text { MD, PhD }\end{array}$ & $\begin{array}{l}\text { University of California San } \\
\text { Francisco }\end{array}$ & $\begin{array}{l}\text { Design and concept; } \\
\text { drafted manuscript }\end{array}$ \\
\hline $\begin{array}{l}\text { Benjamin David } \\
\text { Tolchin, MD, MS }\end{array}$ & Yale School of Medicine & $\begin{array}{l}\text { Design and concept; } \\
\text { revised for } \\
\text { intellectual content }\end{array}$ \\
\hline $\begin{array}{l}\text { Richard J. Bonnie, } \\
\text { LLB }\end{array}$ & University of Virginia & $\begin{array}{l}\text { Revised for } \\
\text { intellectual content }\end{array}$ \\
\hline $\begin{array}{l}\text { Katharina Busl, } \\
\text { MD, MS }\end{array}$ & University of Florida & $\begin{array}{l}\text { Revised for } \\
\text { intellectual content }\end{array}$ \\
\hline $\begin{array}{l}\text { Salvador Cruz- } \\
\text { Flores, MD }\end{array}$ & $\begin{array}{l}\text { Paul L. Foster School of } \\
\text { Medicine Texas Tech University } \\
\text { Health Sciences Center }\end{array}$ & $\begin{array}{l}\text { Revised for } \\
\text { intellectual content }\end{array}$ \\
\hline $\begin{array}{l}\text { Leon G. Epstein, } \\
\text { MD }\end{array}$ & $\begin{array}{l}\text { Northwestern University } \\
\text { Feinberg School of Medicine }\end{array}$ & $\begin{array}{l}\text { Revised for } \\
\text { intellectual content }\end{array}$ \\
\hline $\begin{array}{l}\text { Ericka P. Greene, } \\
\text { MD }\end{array}$ & Houston Methodist Hospital & $\begin{array}{l}\text { Revised for } \\
\text { intellectual content }\end{array}$ \\
\hline Judy IIles, CM, PhD & University of British Columbia & $\begin{array}{l}\text { Revised for } \\
\text { intellectual content }\end{array}$ \\
\hline $\begin{array}{l}\text { Matthew } \\
\text { Kirschen, MD, PhD }\end{array}$ & $\begin{array}{l}\text { Children's Hospital of } \\
\text { Pennsylvania }\end{array}$ & $\begin{array}{l}\text { Revised for } \\
\text { intellectual content }\end{array}$ \\
\hline $\begin{array}{l}\text { Daniel G. } \\
\text { Larriviere, MD, JD }\end{array}$ & $\begin{array}{l}\text { Inova Neuroscience and Spine } \\
\text { Institute }\end{array}$ & $\begin{array}{l}\text { Revised for } \\
\text { intellectual content }\end{array}$ \\
\hline Sneha Mantri, MD & Duke University & $\begin{array}{l}\text { Revised for } \\
\text { intellectual content }\end{array}$ \\
\hline $\begin{array}{l}\text { Michael A. Rubin, } \\
\text { MD }\end{array}$ & $\begin{array}{l}\text { University of Texas } \\
\text { Southwestern Medical Center }\end{array}$ & $\begin{array}{l}\text { Revised for } \\
\text { intellectual content }\end{array}$ \\
\hline $\begin{array}{l}\text { Barney J. Stern, } \\
\text { MD }\end{array}$ & Johns Hopkins University & $\begin{array}{l}\text { Revised for } \\
\text { intellectual content }\end{array}$ \\
\hline $\begin{array}{l}\text { Lynne P. Taylor, } \\
\text { MD }\end{array}$ & University of Washington & $\begin{array}{l}\text { Revised for } \\
\text { intellectual content }\end{array}$ \\
\hline
\end{tabular}




\section{References}

1. Kesselheim AS, Avorn J. Approving a problematic muscular dystrophy drug: implications for FDA policy. JAMA. 2016;316(22):2357-2358.

2. Chen EY, Haslam A, Prasad V. FDA acceptance of surrogate end points for cancer drug approval: 1992-2019. JAMA Intern Med. 2020;180(6):912-914.

3. Baden LR, Solomon CG, Greene MF, D'Agostino RB, Harrington D. The FDA and the importance of trust. N Engl J Med. 2020;383(27):e148.

4. Alexander GC, Knopman DS, Emerson SS, et al. Revisiting FDA approval of aducanumab. N Engl J Med. 2021;385(9):769-771.

5. Richard E, den Brok MGHE, van Gool WA. Bayes analysis supports null hypothesis of antiamyloid beta therapy in Alzheimer's disease. Alzheimers Dement. 2021;17(6):1051-1055.

6. Mahase E. Three FDA advisory panel members resign over approval of Alzheimer's drug. BMJ. 2021;373:n1503.

7. Cubanski J, Neuman T. FDA's Approval of Biogen's New Alzheimer's Drug Has Huge Cost Implications for Medicare and Beneficiaries. Kaiser Family Foundation; 2021. Accessed July 22, 2021. kff.org/medicare/issue-brief/fdas-approval-of-biogens-newalzheimers-drug-has-huge-cost-implications-for-medicare-and-beneficiaries/

8. Werble C. Health Policy Brief: Medicare Part B. Health Affairs; 2017. Accessed July 22, 2021. healthaffairs.org/do/10.1377/hpb20171008.000171/full/

9. Beauchamp TL, Childress JF. Principles of Biomedical Ethics, 8th ed. Oxford University Press; 2019.

10. Alzheimer's Association. Alzheimer's disease facts and figures. Alzheimers Dement. 2021;17(3).
11. Anderson TS, Ayanian JZ, Souza J, Landon BE. Representativeness of participants eligible to be enrolled in clinical trials of aducanumab for Alzheimer disease compared with Medicare beneficiaries with Alzheimer disease and mild cognitive impairment. JAMA. 2021;326(16):1627-1629.

12. Biogen. Financial Update: ADUHELM Investor Webcast [Presentation]. Biogen; 2021. Accessed July 22, 2021. investors.biogen.com/static-files/052ec969-0beb-4f93-aff37e88fde6ab64\#page $=26$

13. Cubanski J, Neuman T. Relatively Few Drugs Account for a Large Share of Medicare Prescription Drug Spending. KFF; 2021. Accessed July 22, 2021. kff.org/medicare/ issue-brief/relatively-few-drugs-account-for-a-large-share-of-medicare-prescriptiondrug-spending/

14. Keehan SP, Cuckler GA, Poisal JA, et al. National health expenditure projections, 2019-28: expected rebound in prices drives rising spending growth. Health Aff. 2020; 39(4):704-714.

15. Manly JJ, Glymour MM. What the aducanumab approval reveals about Alzheimer disease research. JAMA Neurol. 2021;78(11):1305-1306.

16. Chiong W, Tsou AY, Simmons Z, Bonnie BJ, Russell JA. Ethical considerations in dementia diagnosis and care: AAN position statement. Neurology. 2021;97(2): 80-89.

17. Saltzman J. Mass General Brigham Won't Offer Biogen's New Alzheimer's Drug. Boston Globe; 2021. Accessed October 4, 2021. bostonglobe.com/2021/09/28/business/ mass-general-brigham-wont-offer-biogens-new-alzheimers-drug/

\section{NPub.org/patient Offers Important Information to Patients and Caregivers}

The Neurology ${ }^{\circledR}$ Patient Page provides:

- A critical review of ground-breaking discoveries in neurologic research that are written especially for patients and caregivers

- Up-to-date patient information about many neurologic diseases

- Links to additional information resources for neurologic patients

All Neurology Patient Page articles can be easily downloaded and printed, and may be reproduced to distribute for educational purposes. Access NPub.org/patient for a complete index of Patient Pages.

\section{Visit the Neurology ${ }^{\otimes}$ Resident \& Fellow Website}

Click on Residents \& Fellows tab at Neurology.org.

Now offering:

- Neurology Resident \& Fellow Editorial team information

- "Search by subcategory" option

- E-Pearl of the Week

- Direct links to Career Planning and AAN Resident \& Fellow Pages

- Recently published Resident \& Fellow articles

- Commentaries by Editors and Resident \& Fellow team members

f Find Neurology Residents \& Fellows Section on Facebook: facebook.com/AANResidentsAndFellows

Follow Neurology on Twitter: @GreenJournal \#NeurologyRF

(0) Find Neurology Residents \& Fellows Section on Instagram: @aanbrain \#NeurologyRF 


\section{Neurology}

\section{Decisions With Patients and Families Regarding Aducanumab in Alzheimer Disease, With Recommendations for Consent: AAN Position Statement \\ Winston Chiong, Benjamin David Tolchin, Richard J. Bonnie, et al. Neurology 2022;98;154-159 Published Online before print November 17, 2021}

DOI 10.1212/WNL.0000000000013053

\section{This information is current as of November 17, 2021}

\section{Updated Information \&} Services

References

Subspecialty Collections

Permissions \& Licensing

Reprints including high resolution figures, can be found at: http://n.neurology.org/content/98/4/154.full

This article cites 10 articles, 2 of which you can access for free at: http://n.neurology.org/content/98/4/154.full\#ref-list-1

This article, along with others on similar topics, appears in the following collection(s):

All Neuropsychology/Behavior

http://n.neurology.org/cgi/collection/all_neuropsychology_behavior Alzheimer's disease

http://n.neurology.org/cgi/collection/alzheimers_disease

Insurance

http://n.neurology.org/cgi/collection/insurance

MCI (mild cognitive impairment)

http://n.neurology.org/cgi/collection/mci_mild_cognitive_impairment Professional conduct and ethics

http://n.neurology.org/cgi/collection/professional_conduct_and_ethics

Information about reproducing this article in parts (figures,tables) or in its entirety can be found online at:

http://www.neurology.org/about/about_the_journal\#permissions

Information about ordering reprints can be found online:

http://n.neurology.org/subscribers/advertise

Neurology ${ }^{\circledR}$ is the official journal of the American Academy of Neurology. Published continuously since 1951, it is now a weekly with 48 issues per year. Copyright @ 2021 American Academy of Neurology. All rights reserved. Print ISSN: 0028-3878. Online ISSN: 1526-632X.



